\title{
Uses and Roles of the Relative Pronouns
}

\author{
Yoon-Jin Lee ${ }^{1}$, Mun-Koo Kang ${ }^{2}$ \\ ${ }^{1}$ College Lecturer, Dept.of Liberal Education, Kongju National Univ., Korea, xcoiicox@naver.com \\ ${ }^{2}$ Professor, Dept. of English, Kongju National Univ., Korea, kangmunkoo@ hanmail.net
}

Corresponding author: Mun-Koo Kang

\begin{abstract}
This study analyzes English relative pronouns grammatically and explores the teachings methods through which Korean learners can easily understand the meaning and usage of English relative pronouns that do not exist in their native language. In Chapters 2 and 3, this study refers to the thoughts of past scholars and lists the definition and types of the relative pronoun to analyze its characteristics. The common definition is that the relative pronoun serves as both the pronoun and the conjunction. Types of relative pronouns include common relative pronouns, compound relative pronouns, and pseudo-relative pronouns. To study the use of the relative clause containing the relative pronoun, the researchers consider the usage of relative clauses, restrictive and non-restrictive relative clauses, and examine their differences. There is a semantic and structural difference between the two usages, so one should choose to employ one or the other according to the text. Furthermore, this study presents effective teaching methods for relative pronouns that can help motivate student interest from an educational aspect. In conclusion, the instructor should explain the grammatical knowledge about the relative pronoun and the relative clause, and then have students in pairs or groups practice the sentences and notice their weaknesses, so that the grammar is internalized within them.
\end{abstract}

Keywords: Relative Pronouns, Relative Clauses, Postnominal, Restrictive Usage, Non-restrictive Usage

\section{Introduction}

One of the grammar items that Korean English learners have difficulty with is relative pronouns. The reason why learners feel they are the most difficult and have a hard time learning them has to do with the difference in word order between Korean and English. To be more specific, the Korean language and English language have different modification structures. English has post-modifying structures with relative clauses while Korean doesn't have post-modifying structures and relative clauses. So instructors have to acknowledge the difficulties that students have when they learn English relative pronouns, and consider how to teach them more effectively (Yu-Jeong, Lee, 2009)[1]. On top of this, the types and roles of the relative clauses differ by the noun they modify, which explains the difficulty experienced by EFL learners. Thus, the purpose of this study is to explore various teaching and learning methods for learners to engage in more natural learning of relative pronouns.

To understand the theoretical background of relative pronouns, the theories of relative pronouns were considered by exploring how some of the representative scholars defined them. The researchers will divide relative pronouns into categories and explore how those in each category behave differently: common relative pronouns, compound relative pronouns, and pseudo-relative pronouns.

This study also divides the usage of the relative pronoun into restrictive usage and non-restrictive

Received: May 16, 2021; $1^{\text {st }}$ Review Result: July 01, 2021; $2^{\text {nd }}$ Review Result: August 18, 2021 Accepted: September 30, 2021 
usage and looks more closely into the sentence structures and the grammatical forms.

Therefore, to assist learners who have difficulty learning relative pronouns, the instructor should explain the grammatical knowledge about the relative pronoun and the relative clause, and then, have students in pairs or groups practice the sentences and notice their weaknesses, so that the grammar is internalized within them. The conclusion of this study will attempt to suggest effective English teaching methods for teaching relative pronouns.

\section{Definition and Types of Relative Pronouns}

\subsection{Definition of Relative Pronouns}

Advance research on relative pronouns commonly defines it as serving the role of both the pronoun and the conjunction. An English pronoun refers to an antecedent, a noun that appears before it, or a noun that does not yet appear in the sentence. Conjunctions connect two words, two phrases, or two clauses; examples include and, but, therefore, and so on. The combination of these two parts of the category is the relative pronoun, through which repetition is avoided and two sentences are connected.

Quirk \& Greenbaum(1973)[2] classified pronouns into personal pronouns, reflexive pronouns, relative pronouns, interrogative pronouns, demonstrative pronouns, and indefinite pronouns; and relative pronouns hold the meaning of 'making a relation', which includes the function of the conjunction. Thus, relative pronouns serve as both pronouns and conjunctions, and the relative clause containing the relative pronoun appears after the antecedent and modifies it, and, in this sense, it is an adjectival phrase. Other scholars such as Yule, G(1998)[3] stated that relative pronouns appear in the post-nominal position, providing information about a person or an object that the noun refers to. According to Murphy, R (2002)[4], relative pronouns give information about a person or an object through the relative clause.

\subsection{Types of Relative Pronouns}

\subsubsection{Common Relative Pronouns}

Common relative pronouns include who, which, that, and what. Relative pronouns can be classified according to the case as follows (Jae-Jin Jang, 2001, p. 146)[5].

[Table 1] Classification of Relative Pronouns according to Case

\begin{tabular}{|c|c|c|c|c|}
\hline $\begin{array}{c}\text { Antecedent } \\
\text { case }\end{array}$ & Person & Thing & Person/animal/thing & $\begin{array}{c}\text { Thing(including its } \\
\text { antecedent }\end{array}$ \\
\hline Nominative & Who & Which & That & What \\
\hline Genitive & Whose & $\begin{array}{c}\text { Whose } \\
\text { of which }\end{array}$ & That & What \\
\hline Accusative & Whom & Which & Adjective & Noun \\
\hline Clause & Adjective & Adjective & The \\
\hline
\end{tabular}

In the perspective of traditional grammar, who occurs when an antecedent is a person, with its variants who for a nominative case, whom for an accusative case, and whose for a genitive case. When the antecedent is an animal or an object, which occurs, with its variants being which for a nominative and accusative case, and of which or whose for a genitive case. When a person, an animal, or a thing appears as the antecedent, who and which can be substituted with that; that does not change in form 
for a nominative or accusative case.

1) Who

Who occurs when it appears in the subject position in the relative clause and when its antecedent refers to a person. Thus, the relative pronoun usually occurs with an antecedent that refers to a person, and when it refers to general people, the relative pronoun can take one of those who, one who, or he/she who.

2) Whom

Whom is an accusative relative pronoun that functions as the object in the relative clause, and when the antecedent refers to a person? In Modern English whom occurs less frequently in colloquial speech or informal writing and is either replaced by who or is omitted.

3) Whose

In Modern English, the relative pronoun whose is a genitive case of who and which and occurs to indicate possession of its antecedent. Antecedents that frequently occur before whose include humans, animals, objects, and nouns that refer to groups, such as organizations or society(Cowan, R, 2013)[6].

4) Which

With the development of Modern English into the nineteenth century, the scope of usage for the relative pronoun had been narrowed to refer to objects and animals, not persons. Sung-Shik Cho(1971, p. 331)[7] states that until the eighteenth century, the relative pronoun which had been used to modify an antecedent that referred to a person and that it was not until recently that who and which started to refer to inanimate entities.

5) What

What (that which=the thing which=all that=the man that) includes its antecedent in itself and appears in the nominative or accusative case, usually functioning as a noun phrase that occurs in the subject, object, or complement position. It does not refer to any antecedent before it and is regarded as an independent clause; it functions as the object of a subject, predicate, verb, or preposition (SungShik Cho, 1977)[8]. But besides such nominal usage, it sometimes is inserted within a sentence, and serves as a relative adjective as that of which, and modifies the noun that appears immediately after it. The sentential structure in which what occurs is an incomplete sentence without the subject or the object.

6) That

The relative pronoun has made its appearance in Old English and is the longest existing grammar compared to the other relative pronouns. In Old English, Pæt served as either a relative pronoun or a referential pronoun, and its roles have been restricted with the appearance of who and which in Modern English(Jong-Uk Choi, 2000, p.199)[9]. Also, as the tendency strengthened in which who is used to refer to a person and which is used to refer to an object, it is reasonable that the use of that relative weakness. Another reason for the less use of that has to do with its strong characteristic as relative conjunction compared to who or which, and it is used restrictively, and never nonrestrictively. Thus, the role of that has weakened compared to who or which, but the fact that it can occur with either a human antecedent or an object antecedent assigns grammatical importance to that. Besides the theory on the relative pronoun that suggested by Jespersen, O (1956, pp.361-362)[10], let us look into other theories as well. Generally, that in the relative clause has been referred to as the relative pronoun, but Bas Aarts (2011, pp.179-202)[11] maintains that it is not a relative pronoun; it is subordinate conjunction that introduces the relative clause. The reason that Bas Aarts made such an argument is that pronouns can occur as the complement of a preposition (to whom/to which), but the same does not apply to the conjunction that (*the person to that). Thus, it can be regarded as the collapse of the conjunctive function (Mun-Koo Kang, 2017)[12]. Let us consider some examples from Bas Aarts (2011, pp.179-202)[11].

(1) The power [clause that Ørel enables this union] Coleridge categorized as the imagination. 
In (1), there is no overt relative constituent; but there is a covert relative phrase expressed as 'Ørel' meaning implicit relative elements. The antecedent of that is not power; that of the covert relative phrase before that is, and this relative phrase acts as the subject.

\subsubsection{Compound Relative Pronouns}

A compound relative pronoun is a combination of a noun and a relative pronoun into one word; it is an addition of -ever at the end of general relative pronouns who, what, that, which, resulting in whoever, whichever, whatever. As general relative pronouns serve various grammatical functions in a sentence, compound relative pronouns differ in their usage depending on the function, but usually, they introduce noun phrases or concessive adverb phrases. Also, there were more cases in whichsoever is added at the end instead of -ever, and they are rarely used in Modern English (Sung-Shik Cho, 1983, pp. 382-384)[13].

[Table 2] Types of Compound Relative Pronouns

\begin{tabular}{|c|c|c|c|}
\hline Item & Person & Object & Person/object \\
\hline Nominative & Whoever(=anyone who/that $)$ & Whatever(=anything which/that $)$ & $\begin{array}{c}\text { Whichever(=anyone who/that: person) } \\
\text { (=anything which/that: object })\end{array}$ \\
\cline { 1 - 2 } Accusative & Who(m)ever(=anyone who(m)/that) & & \\
\hline Genitive & Whosever(=anyone whose $)$ & & \\
\hline
\end{tabular}

As presented in [Table 2], whoever changes in form into whoever or whomever, depending on the case. In a sentence, a noun can occur immediately after whatever or whichever, and they serve as the compound relative adjective. The meaning of each compound relative pronoun is as follows: whoever $=$ anyone who, whichever $=$ anything which, whatever $=$ anything that. Thus, they are classified according to the case of the word they modify, and they are relative pronouns that include anyone or anything as the antecedent. Therefore, while relative clauses precede an adjective clause that modifies the antecedent, compound relative pronouns precede a noun clause. Let us consider some examples in which compound relative pronouns precede a noun clause.

(2) a. Whoever comes is welcome.

b. Buy whichever you like.

c. Do whatever you like.

As mentioned above, compound relative pronouns are followed by a concessive adverb clause; such a case emphasizes the non-restrictiveness and supports the concessive meaning. Adverb phrases following a compound relative pronoun are separated from the matrix clause with a comma.

(3) a. Whichever they choose, we must accept their decision.

b. Whomever you meet, try not to prejudge them.

c. Whoever telephones, tell him I'm out.

\subsubsection{Pseudo-relative Pronouns}

Pseudo-relative pronouns serve a similar role as relative pronouns but they do so in a sentence of a different structure than relative pronouns such as which, that, and what. There are three pseudorelative pronouns, - as, then, and but - which are also classified as conjunctions. But they change in the case in a sentence, modifying the noun that occurs before the clause following them. In such a sentence, it is important to note the correlative words that occur with the antecedent. In other words, as, but, and then occur with certain antecedents and serve the role as relative pronouns. But compared to common relative pronouns, pseudo-relative pronouns are those that serve merely a secondary role.

1) as

As one of the pseudo-relative pronouns, as occurs with either as, such, or the same as its antecedent. 
Additionally, it occurs in a sentence in which the antecedent is a part of or the entire sentence that precedes it. The structure in which the pseudo-relative pronoun as occurs is 'As + adjective + antecedent + as'; the latter as is understood as having the same meaning as who or which. As such, there are many cases when the antecedent is fined, so it is rather less difficult to identify the pseudorelative pronoun as (Sung-Shik Cho, 1983, pp. 384-388)[13]. Let us consider the following examples.

(4) As many apples as(=which) were harvested from her farm were sold out in half an hour.

2) but

Another type of pseudo-relative pronoun but occurs when a negation word as 'no, never, not, few, little, scarcely, hardly' appears in the antecedent, and is a nominative relative pronoun. The pseudorelative pronoun but can be replaced with 'that (who / which) not'; the reason why there is no negation word in the sentence following but is that it has already occurred before it, indicating that but implies a meaning of negation. As can be seen in the following, sentences containing the pseudorelative pronoun but often begin with There is in the matrix clause. But in Modern English, the pseudo- relative pronoun but does not occur frequently; it is seen rather more in proverbial expressions.

(5) a. There is no rule but has some exceptions.

b. There is no one but loves him.

3) than

The pseudo-relative pronoun then occurs when there is a comparative expression in the antecedent or when the antecedent is a noun modified by one. Thus, when used as a relative pronoun, then always occurs with a comparative expression. To clarify, let us look at the following example.

(6) a. More people than I had expected were present.

b. Don't use more words than are necessary.

\section{Usage of Relative Pronouns}

The relative clause introduced by the relative pronoun can be divided into two usages: restrictive usage and non-restrictive usage. First, a relative pronoun that imposes a restriction on the antecedent is called the restrictive relative pronoun, while a relative pronoun that does not restrict the antecedent and gives additional information on it is called the non-restrictive relative pronoun. In the restrictive usage, the antecedent and the restrictive relative clause is close in relation and there is no pause in between, while in the non-restrictive usage, the antecedent and the restrictive relative clause is not closely related, and there should be a comma in between (Sung-Shik Cho, 1971, p. 324)[7]. Also, the restrictive relative pronoun restricts or constrains the antecedent and offers necessary information on it for confirmation, while the non-restrictive relative pronoun does not restrict the antecedent in the matrix clause but provide additional information (Celce-Murcia, M. \& Larsen-Freeman, D, 1983, P.594)[14].

\subsection{Restrictive Usage}

The restrictive usage does not have a comma before the relative pronoun, and the relative clause modifies the antecedent before it. Thus, it gives semantic restriction on the antecedent, while modifying and interpreting the antecedent when it gives specific information on the antecedent to refer to a type of person or an object. Relative pronouns in the restrictive usage include who, which, and that. As mentioned above, the relative clause and the antecedent are closely related; Curme, G, $\mathrm{O}(1947)[15]$ also stated that the restrictive relative clause has a semantically close relationship with the antecedent and occur without a pause, and the two clauses are not separated with a comma. To look at the characteristics of restrictive usage, let us consider the following examples. 
(7) a. I stayed at the hotel that John recommended to me.

b. I have a son who speaks English well.

In (7a), the same is true in that the hotel John recommended is a particular hotel. There is also a restriction on the antecedent in ( $7 \mathrm{~b}$ ) in that it is unknown how many sons the subject ' $\mathrm{I}$ ' has, and the son who speaks English well is one. As seen in the above sentences, the restrictive usage does not accompany a comma, in which the relative clause directly modifies the antecedent, imposing the restriction, and has a close relationship with it.

1. Prepositions can occur in a restrictive relative clause, in which who, which, or that in the restrictive usage acts as the object of the preposition.

(8) a. There are many factors that we have no control over.

b. That is the reality of the world that we live $\underline{\text { in}}$.

2. The following is when there is a double-restriction in which two clauses restrict the antecedent (Jespersen, O, 1961, P.358)[16].

(9) a. There is nothing that I can do and that will satisfy you.

b. There are many items, which are necessary to live on, which we have long hoped to buy.

3. The following is when the relative pronoun has been omitted in the restrictive usage. The accusative relative pronoun is commonly omitted in informal English, while the nominative relative pronoun is not omitted.

(10) a. I need to talk to someone $\boldsymbol{\varnothing}$ I can really trust.

b. The architect who designed this building won an award.

\subsection{Non-restrictive Usage}

In non-restrictive usage, the relative pronoun is accompanied by a comma before it. Unlike the restrictive usage where the relative pronoun explains what kind of person or object the antecedent refers to, there is no restriction on the antecedent and the purpose is to supplement with additional information; the meaning is interpreted from the beginning to the end of a sentence. Such relative pronouns that give descriptive explanation are called the non-restrictive relative pronouns; the clause they occur in are called non-restrictive relative clauses. Let us look at the context in which the nonrestrictive usage is employed.

1. In non-restrictive usage, a comma separates the antecedent and the relative clause in writing; in speaking, they are separated with a lower tone.

(11) a. My uncle, who lives in the same apartment, is a teacher.

b. We stayed at the Lotte Hotel, which Tom recommended to us.

2. When the antecedent is a proper noun referring to a particular person, name, or place.

(12) a. I've just come back from England, where Amy lives.

b. Yesterday I met a woman named Jenny, whose husband works in LA.

3. Non-restrictive relative clauses do not allow the occurrence of that or what. That has a strong conjunctive characteristic, which indicates that it also has a strong characteristic of a compliment.

(13) a. I have a toy, which is really cute.

b. Tom, who speaks English, works as a tourist guide.

4. The antecedent can take the form of a noun or an entire sentence.

(14) a. The team has lost again, which doesn't surprise me.

b. I get paid a bit more now, which means I can afford to run a car.

5. Numerals like all, one, some can occur with of whom or of which to refer to a part of the whole.

(15) There are hundreds of TV channels, some of which operate 24 hours a day.

Also, informal English, numerals sometimes occur after whom or of which.

(16) The company plans to open eleven new outlets, of which six will be in Korea. 
6. Prepositions can occur before the relative pronoun or at the end of the added clause.

(17) a. Jim's hobby is golf, on which she spends most of her spare cash.

b. Jim's hobby is golf, which she spends most of her spare cash on.

7. No, any, everyone, body, thing do not occur as the antecedent in a non-restrictive clause (Huddleston \& Pullum, 2002, p.1060)[17].

(18) *Any man who goes back on his word, is no friend of mine.

\subsection{Differences between the Restrictive Usage and the Non-restrictive Usage}

Restrictive clauses are subordinate in meaning to the clause containing the antecedent, while continuative clauses are more independent. The differences between the restrictive and non-restrictive usages are listed in the following.

[Table 3] The Restrictive Usage and the Non-restrictive Usage

\begin{tabular}{|c|c|c|c|c|}
\hline & \multicolumn{2}{|c|}{ Restrictive usage } & \multicolumn{2}{|c|}{ Non-restrictive usage } \\
\hline & Personal & Non-personal & Personal & Non-personal \\
\hline Nominative & Who, that & Which, that & Who & \multirow{2}{*}{ Which } \\
\hline Accusative & Whom, that, zero & Which, that, zero & Whom & \\
\hline Genitive & & Wh & & \\
\hline
\end{tabular}

1. Relative pronouns who and which occur both in a restrictive clause and a non-restrictive clause, while that does not occur in a non-restrictive clause.

2. Due to the difference in form between the two usages, while in the restrictive usage, the antecedent and the restrictive clause have a close relationship and do not accompany a comma or tone difference to separate them, the non-restrictive usage is more independent and the two are separated with a comma or tone.

3. In the restrictive usage, the accusative relative pronoun can be omitted, while it is not the case in the non-restrictive usage since its role is to provide additional information on the antecedent.

4. Restrictive clauses that modify a common antecedent are mostly in a conditional relation, with a similar meaning of the adverb clause if-clause; in a non-restrictive clause, it is common to denote the meaning of reason, as with because or for. Consider the following sentences.

(19) a. He thanked his friend, who had been very helpful.

b. Jim's hobby is golf, which she spends most of her spare cash on.

\subsection{Omission of the Relative Pronoun}

In a contact relative clause, the antecedent and the relative clause are in a very close relationship, and there is no grammatical need for a relative pronoun to connect the two clauses. In this respect, Jespersen, O (1965, p.134)[18] stated that the antecedent is restricted, and it has a very close relationship with the relative clause that even without a relative pronoun, the meaning is clear enough. Because the subordinate clause following the matrix clause is clearly represented, and one word in the matrix clause has a very close relationship with the relative clause, in which it restricts and modifies the antecedent, the meaning of the sentence stays the same even without a relative pronoun. Let us look at the cases where the relative pronoun can be omitted.

1. When the relative pronoun is the object of an intransitive verb

(20) a. That is my new teacher (whom) I met three days ago.

b. This is the car (which) he wanted to buy.

2. When the relative pronoun is the object of a preposition 
If the antecedent is the object of a preposition, the preposition is left at the end of the sentence and the accusative relative pronoun is omitted. Consider the following.

(21) a. She is my girlfriend (who) I went to see the movie with.

b. He has no friend (whom) he can depend upon.

3. When the relative pronoun is in the form "nominative relative pronoun + be verb before a participle

(22) a. The help is a novel by an American author (who/that is) named Kathryn Stockett.

b. It provides children disaster zones with special soccer balls (which/that are) from aid boxes.

4. When the relative pronoun is the nominative of Here is, It is, What is, Who is or There is

(23) a. There is a girl (who) wants to see you.

b. Who was it (that) invented the radio?

5 . When the relative pronoun is the nominative of the predicate

(24) a. She is not the cheerful woman (that) she was before.

b. He is not the doctor (that) he was seven years ago.

\section{Conclusions}

This study examined the theories of the relative pronoun suggested by many scholars based on their types and uses. The most important point in understanding the relative pronoun is that it serves a pronominal and conjunctive role. When combining two sentences into one, the noun that is repeated or overlapped is called the antecedent, which occurs immediately before the relative pronoun. The relative clause restricts the noun, so functionally, it is an adjective. Thus, the relative pronoun can only occur when there is an overlapping element in two sentences, and the structure is 'antecedent + relative pronoun'.

Types of relative pronouns include common relative pronouns, compound relative pronouns, and pseudo-relative pronouns. Relative pronouns are most familiar to us, such as who, whose, whom, what, which, and that are common relative pronouns; compound relative pronouns include whoever, whichever, and whatever; lastly, pseudo-relative pronouns include as, but, and then. For common relative pronouns, when the antecedent refers to a person, who, whose, or who occurs; when it refers to an animal or an object, which, of which, or whose occurs. The relative pronoun that can occur regardless of whether the antecedent refers to a person or a thing, and it can occur only in nominative or accusative case. It also showed that Bas Aarts argued that is not a relative pronoun but subordinate conjunction in his theory. The relative pronoun includes its antecedent in itself and occurs in either nominative or accusative case, with the clause following it an incomplete sentence. What-clauses are noun clauses and occur in either the subject, complement, or object position.

The study suggested the difference between the restrictive usage and the non-restrictive usage of the relative pronoun. The most obvious way to distinguish between the two is the formal difference, the use of the comma. In restrictive usage, the relative pronoun has a close grammatical relationship with its antecedent and cannot be separated. In the non-restrictive usage, on the other hand, the relative clause provides additional information about the antecedent and can be separated from the matrix clause with a comma (Yang-Soon Kim, et al, 2000)[19]. Next, is the omission of the relative pronoun. When the relative pronoun is in the object position of a verb or a preposition, it can be omitted; the relative pronoun that cannot occur in such a context.

To draw a conclusion based on this study, the relative pronoun is the most unfamiliar and difficult subject of grammar for learners whose target language is English. It is an important aspect of the current English curriculum in that it is a frequent grammar item on KSAT every year. Hence, teaching the subject in a memorization-based method using grammar exercises will lower students' interest in it; the problem gets worse as the grade advances with longer texts and more complicated structures of 
the relative pronoun, which may cause to take more time for learners to interpret the sentences. Therefore, the teacher is required to have a systemized knowledge of the relative pronoun according to the different levels of learners and to help them understand that the relative pronoun is not a grammar item to memorize but a language that differs in structure from their first language. Also in order to reduce students' error in the use of relative pronouns, a teacher should engage them in various activities that provide students with examples of how relative pronouns are used in different contexts. Both teachers and students will have a better grasp of how to teach or use relative pronouns in an appropriate manner.

The first method is form-focused language instruction in which various methods are used to stimulate learners' interest and to help them develop natural learning of grammar forms. Based on such aspects of form-focused language instruction, we will look into effective teaching methods for relative pronouns. The major reason why learners think of relative pronouns as difficult to learn has something to do with the difference in language structure between English and their mother tongue, which resulted in the difficulty to interpret sentences in which relative clauses occur. A relative clause is an inserted clause, which is inserted in locations within a sentence; this makes it difficult to interpret the meaning of the entire sentence at once. As indicated by Kuno, S(1974)[20]'s theory of the difficulty level in acquiring relative clauses (OS-OO-SS-SO, etc), learners find it troublesome to interpret the sentence because, unlike in other sentences, the subject, and the verb are located far apart from each other, as is the case in which the antecedent serves as the subject of the matrix clause and as the object in the relative clause. As students advance their grades yearly, the English sentences they encounter also increase in length, and this can affect their reading comprehension greatly. Therefore, students are recommended to practice a lot of sentences containing the relative pronoun, which necessitates a teaching method through which students develop the ability to interpret sentences containing the relative pronoun at one glance. Each interview sheet of three participants was revealed in order to check their understanding of the relative pronoun through the form-focused instruction.

[Table 4] Interview (Boram High School Participants)

\begin{tabular}{|c|l|}
\hline Activity examples & $\begin{array}{l}\text { 1. The students (the students arrived late) missed the announcement. } \\
\rightarrow \text { The students who arrived late missed the announcement. } \\
\text { 2. The bus (the bus is supposed to leave at 10) was delayed. } \\
\rightarrow \text { The bus which is supposed to leave at 10 was delayed. }\end{array}$ \\
\hline Ye-Rin & $\begin{array}{l}\text { In one 1example, the subject of the sentence, the students, and the students in the parentheses are the } \\
\text { same noun phrase. }\end{array}$ \\
\hline Min-Ju & $\begin{array}{l}\text { A relative pronoun occurs in order to prevent repetition and redundancy; in this case, the students refer to } \\
\text { people and the relative pronoun who is employed. }\end{array}$ \\
\hline So-Ra & $\begin{array}{l}\text { In 2example, the subject The bus and the bus in parentheses are the same, so one is omitted and replaced } \\
\text { by the relative pronoun, which results in the sentence. }\end{array}$ \\
\hline
\end{tabular}

In order for learners to conduct such exercise on their own, they should be taught to engage in multiple repetitions of constructing sentences using the relative pronoun according to different antecedents, so that they understand the form and usage of relative clauses. Form-focused language instruction can be an effective teaching method in that the communicative language teaching itself is not sufficient to improve accuracy; and without incorporating form-focused language instruction, fossilization may take place in learners' interlanguage This is why a teaching method like formfocused language instruction is needed, which accounts for the characteristics and rule about grammatical structure in English that are nonexistent in learners' first language.

The second method presented in Task-Based on Language Teaching, in which learners participate in pair or group activities and communicate in the target language to accomplish a given task, while realizing how useful the activity is in improving their language proficiency. Task-based language 
teaching can be abbreviated to 'TBLT'. The aim of TBLT is for English learners to complete a task they are participating in without another person's help, discover the problems that arise in the process, and practice on their own to improve their communicative competence. The task in TBLT can be defined as activities through which learners set a specific goal with regard to their target language and constantly practice the language until they accomplish their goal. Nunan, $D(2004)$ [21] emphasized the selection of learning material based on learners' needs, interactive communication, use of real material, importance put on the learning process, activities that reflect learners' experience, and tasks that will be practical in the real world for learners as the necessary principles in applying Task-Based Language Teaching to the classroom. Let us look at the following examples of the specific teaching methods for the relative pronoun, based on Task-Based Language Teaching suggested by Nunan, $\mathrm{D}(2004)[21]$.

(26) The ultimate life force lies in tiny cellular factories (of energy), ((called mitochondria)), (that burn nearly all the oxygen we breathe in).

(An excerpt from 2014 KSAT English Test Type B)

Learners can be given an example sentence like the one above and interpret the sentence on their own, looking for the relative clause and the antecedent, which will lead them to improve their ability to understand how a relative clause is formed. The sentence above is an excerpt from a grammar item from the 2014 KSAT English test, which asks test-takers to find the antecedent of the nominative relative pronoun. First, learners in small groups will look at the entire sentence structure and find out that the phrase ((called mitochondria)) is an inserted phrase, which is an elaboration of the antecedent factories. Then, they will locate the relative pronoun and also see that the sentence following it is an incomplete sentence without a subject. The difficulty of the task can be varied according to the grammar level of learners by offering them different lengths of sentences containing the relative pronoun. Through such comprehensive reading-oriented activities, learners are expected to gradually become familiar with the relative pronoun. The following interview shows answers through the teaching method in which learners are given two sentences and a list of phrases and they are told to write them in the correct order. This is useful for beginner-level learners who only know about the rules of the relative pronoun.

[Table 5] Interview (Boram High School Participants)

\begin{tabular}{|c|l|}
\hline $\begin{array}{c}\text { Activity } \\
\text { example }\end{array}$ & $\begin{array}{l}\text { A satellite is an object which has been sent into space to collect information. } \\
\rightarrow \text { A satellite is an object (information, which, space, into, has been sent, to collect) } \\
\rightarrow \text { A satellite is an object which has been sent into space to collect information. }\end{array}$ \\
\hline Sin-Seok & $\begin{array}{l}\text { This activity made me overcome the difficulty I had experienced when learning relative pronouns. I could construct } \\
\text { sentences using relative pronouns by myself through this practice. }\end{array}$ \\
\hline Hye-Ju & $\begin{array}{l}\text { I could write a sentence using the relative pronoun, and I shared my work with other students and provided feedback } \\
\text { to one another. In the end, we submit our work to the teacher. In the process, I could internalize the grammar } \\
\text { knowledge associated with the concept and use of the relative pronoun. }\end{array}$ \\
\hline
\end{tabular}

Aside from these two methods, this study suggests teaching through games, audio-visual media, and the Internet. Therefore, the instructor should explain the grammatical knowledge about the relative pronoun, and the relative clause, then, have students in pairs or groups practice the sentences and notice their weaknesses, so that the grammar is internalized within them.

\section{References}

[1] Yu-Jeong Lee, Teaching English Relative Pronouns for Korean EFL High School Students, The Graduate School of Education, Chosun University, Master's thesis, (2010) 
[2] R. Quirk, A Concise Grammar of Contemporary English, (Text edition), Houghton Mifflin Harcourt School, (1973)

[3] G. Yule, Explaining English grammar, Oxford : Oxford University Press, (1998), p.182.

[4] R. Murphy, English Grammar in Use for Intermediate Students, Cambridge: Cambridge University Press, (2002), https://forumturbo.org/wp-content/uploads/wpforo/attachments/2/2058-English-Grammar-in-Use-Raymond-MurphyCambridge-2013.pdf

[5] J. J. Jang, Man to Man Basic English, Seoul: Man to Man, (2001), http://www.yes24.com/Product/Goods/3194369

[6] R. Cowan, The Teacher's Grammar of English, Cambridge: Cambridge University Press, (2008)

[7] Sung-Shick Cho, An Advanced English Grammar, Seoul: Korea University Press, (1971), p.324, pp.329-335.

[8] Sung-Shick Cho, The New Standard English Grammar, Seoul: Korea University Press, (1977)

[9] Jong-Wook Choi, A study of English relative pronoun That, English Language \& Literature Teaching, No.6, (2000), pp.199-217,

[10] O. Jespersen, Essentials of English Grammar, (1st Edition), London: Routledge, (2013)

[11] Bas Aarts, Oxford Modern English Grammar, New York: Oxford University Press, (2011) pp.179-202.

[12] Mun-Koo Kang, Modern English Grammar, Seoul: Hankookmunhwasa, (2017)

[13] Sung-Shick Cho, English Grammar Research 1, Seoul: Shinasa, (1983), pp.382-388.

[14] M. Celce-Murcia, D. Larsen-Freeman, The grammar book : an ESL/EFL teacher's course, Rowley, Mass.: Newbury House, (1983), pp.372-373, p.594.

[15] G. O. Curme, Syntax, Boston: Healthy and Company, (1947), https://archive.org/details/englishgrammar00curm/mode/2up?q=restrictive

[16] O. Jespersen, A Modern English Grammar on Historical Principles: Volume 1, Sounds and Spellings, (1st edition), London: Routledge, (2006), p.58, p.358.

[17] R. Huddleston, G. K. Pullen, The Cambridge Grammar of the English Language, (Reprint of 2002 Edition), Cambridge: Cambridge University Press, (2002) pp.1033-1036.

[18] O. Jespersen, Analytic Syntax, (10th edition), The University of Chicago Press, (1984), p.120, p.134, pp.150-154, p.196.

[19] Yang-Soon Kim, Yeon-Mi Park, Jin-Hee Seo, Sook-Hee Choi, Seong- Sim Hong, A Grammar for English Experts, Seoul: Dongin, (2001)

[20] S. Kuno, The position of relative clauses and conjunctions, Linguistic Inquiry, (1974), Vol.5, No.1, pp.117-136.

[21] D. Nunan, Second Language teaching \& learning, Boston: Heinle \& Heinle Publishers, (1998) 